\title{
Effect of Sintering Time on the Densification, Microstructure, Weight Loss and Tensile Properties of a Powder Metallurgical Fe-Mn-Si Alloy
}

\author{
Zhigang Xu ${ }^{1,2}$, Michael A. Hodgson ${ }^{1}$, Keke Chang ${ }^{3}$, Gang Chen ${ }^{4}$, Xiaowen Yuan ${ }^{5}$ \\ and Peng Cao ${ }^{1, *}$ \\ 1 Department of Chemical and Materials Engineering, University of Auckland, Private Bag 92019, \\ Auckland 1142, New Zealand; zxu886@aucklanduni.ac.nz (Z.X.); ma.hodgson@auckland.ac.nz (M.A.H.) \\ 2 School of Automotive Engineering, Wuhan University of Technology, Wuhan 430070, China \\ 3 Materials Chemistry, RWTH Aachen University, D-52056 Aachen, Germany; chang@mch.rwth-aachen.de \\ 4 State Key Laboratory of Porous Metal Materials, Northwest Institute for Non-ferrous Metal Research, \\ Xi'an 710016, China; mychgcsu@163.com \\ 5 School of Engineering and Advanced Technology, Massey University, Private Bag 102904, \\ Auckland 0745, New Zealand; xw.yuan@massey.ac.nz \\ * Correspondence: p.cao@auckland.ac.nz; Tel.: +64-9-923-6924
}

Academic Editor: Hugo F. Lopez

Received: 18 December 2016; Accepted: 28 February 2017; Published: 3 March 2017

\begin{abstract}
This work investigated the isothermal holding time dependence of the densification, microstructure, weight loss, and tensile properties of Fe-Mn-Si powder compacts. Elemental Fe, $\mathrm{Mn}$, and Si powder mixtures with a nominal composition of Fe-28Mn-3Si (in weight percent) were ball milled for $5 \mathrm{~h}$ and subsequently pressed under a uniaxial pressure of $400 \mathrm{MPa}$. The compacted Fe-Mn-Si powder mixtures were sintered at $1200{ }^{\circ} \mathrm{C}$ for $0,1,2$, and $3 \mathrm{~h}$, respectively. In general, the density, weight loss, and tensile properties increased with the increase of the isothermal holding time. A significant increase in density, weight loss, and tensile properties occurred in the compacts being isothermally held for $1 \mathrm{~h}$, as compared to those with no isothermal holding. However, further extension of the isothermal holding time $(2$ and $3 \mathrm{~h}$ ) only played a limited role in promoting the sintered density and tensile properties. The weight loss of the sintered compacts was mainly caused by the sublimation of $\mathrm{Mn}$ in the Mn depletion region on the surface layer of the sintered Fe-Mn-Si compacts. The length of the Mn depletion region increased with the isothermal holding time. A single $\alpha$-Fe phase was detected on the surface of all of the sintered compacts, and the locations beyond the Mn depletion region were comprised of a dual dominant $\gamma$-austenite and minor $\varepsilon$-martensite.
\end{abstract}

Keywords: Fe-Mn-Si alloy; isothermal holding time; powder sintering; density; weight loss; tensile properties

\section{Introduction}

Fe-Mn-Si alloys have been intensively investigated due to the so-called shape memory effect (SME) caused by the reversible phase transformation between face-cantered cubic (fcc) $\gamma$-austenite and hexagonal close-packed (hcp) $\varepsilon$-martensite [1-3]. In the family of metallic shape memory alloys (SMAs), Fe-Mn-Si SMAs exhibit relatively low costs of both raw materials and processing in comparison with their Ni-Ti alloys and Cu-based counterparts [4,5]. This makes Fe-Mn-Si shape memory alloys promising candidates for various civil engineering applications such as pipe joints and rail couplings [6-10]. Recently, temporary biomedical devices such as cardiovascular stents and bone fixation plates have been discussed as potential applications of Fe-Mn-Si alloys due to their reasonable biodegradability, good biocompatibility, and mechanical properties [11-15]. So far, Fe-Mn-Si SMA 
alloys are traditionally fabricated by melting and casting as it is favourable to obtain fully dense bulk materials with homogenized composition.

Powder metallurgy (PM) is a cost-effective metal forming technology that provides various benefits for industrial production in comparison to melting and casting. The products manufactured by PM techniques exhibit a near net shape that requires few or no further machining steps [16-19]. Moreover, it presents the ability to synthesise products with controlled porosity and microstructure [20]. Mechanical milling (MM) is an efficient technique to refine powder particles, which is beneficial for improving the densification and mechanical properties of the PM alloys in the subsequent sintering process [21-24].

In the past, only a few published works have discussed the powder preparation and the sintering behaviors of Fe-Mn-Si alloys using elemental Fe, Mn, and Si powders [25-27]. We sintered mechanically milled Fe-28 wt. \%- $x$ Si powder mixtures with different Si contents $(x)$ at $1200{ }^{\circ} \mathrm{C}$ in a high vacuum furnace, and compared their mechanical and corrosion properties to wrought alloys [11].

It is noted that the sublimation of Mn must be considered when sintering Mn-containing Fe-based alloys in high vacuum, especially those with high Mn concentration $(\geq 20 \mathrm{wt}$. \%). The high vapor pressure of $\mathrm{Mn}$ at high sintering temperatures may lead to the serious sublimation/evaporation of Mn, and consequently change the composition of the sintered Fe-Mn-based alloys [28]. This is harmful to the resulting microstructure and mechanical properties of the sintered compacts. Thus, it is of importance to study the sublimation behaviour of Fe-Mn-Si compacts as a function of the isothermal holding time during vacuum sintering. Currently, the available references on the sublimation/evaporation behaviour of Mn-containing Fe-based alloys mainly focuses on alloys with low Mn content ( $\leq 5 \mathrm{wt}$. \%) [28-30]. We recently reported on the sublimation behaviour of Fe-28Mn-3Si alloys [31] at different sintering temperatures ranging from $1000{ }^{\circ} \mathrm{C}$ to $1200{ }^{\circ} \mathrm{C}$. For the first time, we calculated the sublimation rate of the sintered samples as a function of sintering temperature and discussed the factors that affect the sublimation of the Fe-Mn samples. However, the effect of the isothermal holding time at the sintering temperature on the microstructure and mechanical properties has not yet been reported. It is therefore necessary to reveal how the sublimation rate changes over the isothermal holding time. In this study, we also aim to explore the effect of the isothermal holding on the microstructure and tensile properties of the sintered Fe-28Mn-3Si alloys.

\section{Experiment}

\subsection{Powder Preparation}

Three elemental powders were selected as starting materials in this study: Fe (99.7 wt. \% purity), Mn (99.7 wt. \% purity), and Si (99.9 wt. \% purity). The mean particle sizes of the Fe, Mn, and Si powders are $38.6,38.7$, and $43.4 \mu \mathrm{m}$, respectively. The details on the morphologies and purities of these particles are summarised in our previously published work [11], where the Fe powder exhibits an irregular shape, while both the Mn and Si powders are of angular shape.

Powder mixtures with a nominal composition of $69 \% \mathrm{Fe}, 28 \% \mathrm{Mn}$, and $3 \% \mathrm{Si}$ (all in weight percent) were prepared by $10 \mathrm{~h}$ mixing and subsequent $5 \mathrm{~h}$ mechanical milling (MM) in a planetary ball mill (Pulverisette 6, Fritsch, Idar-Oberstein, Germany) under Ar protection to avoid the oxidation of the powders. More details on the MM parameters are available elsewhere [11].

\subsection{Press and Sinter}

The MM powder mixtures were then compacted in a rectangular die under a pressure of $400 \mathrm{MPa}$ at room temperature. The dimensions of the green compacts were $40 \mathrm{~mm} \times 16 \mathrm{~mm} \times 4.2 \mathrm{~mm}$, and the green density of the ball milled Fe-Mn-Si compacts was $\sim 65 \%$, as determined in reference [15]. The green compacts were subsequently sintered in a high vacuum furnace with a vacuum level of $5 \times 10^{-3} \mathrm{~Pa}$. The heating ramp was $10^{\circ} \mathrm{C} / \mathrm{min}$ below $800{ }^{\circ} \mathrm{C}$ and $5{ }^{\circ} \mathrm{C} / \mathrm{min}$ above $800{ }^{\circ} \mathrm{C}$. All samples were sintered at $1200^{\circ} \mathrm{C}$ with a wide range of isothermal holding times from 0 to $3 \mathrm{~h}$, as shown in 
Figure 1 . The cooling was carried out in the furnace under high vacuum $\left(5 \times 10^{-3} \mathrm{~Pa}\right)$ with an average cooling rate of $60^{\circ} \mathrm{C} / \mathrm{min}$ if the temperature was above $600^{\circ} \mathrm{C}$.

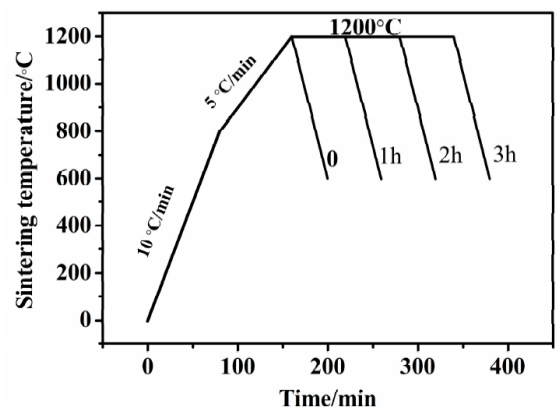

Figure 1. Heating profile of the Fe-28Mn-3Si powder mixture sintered at $120{ }^{\circ} \mathrm{C}$ for different isothermal holding times.

\subsection{Characterisation and Analysis}

The density and open porosity of all the sintered alloys were evaluated by the Archimedes' principle according to the standard ASTM B962-14 [32]. The measurement used distilled water as the immersing medium in air at $25^{\circ} \mathrm{C}$. The theoretical density of a pore-free Fe-28Mn-3Si alloy is $7.50 \mathrm{~g} / \mathrm{cm}^{3}$ [11]. The relative density, $\mathrm{R}$ (percentage of theoretical density), was introduced to reflect the densification of the sintered compacts, and calculated by $R=\rho_{s} / \rho_{t}$ where $\rho_{\mathrm{t}}$ is the theoretical density of the fully dense Fe-28Mn-3Si alloy (i.e., $7.50 \mathrm{~g} / \mathrm{cm}^{3}$ ), and $\rho_{\mathrm{s}}$ is the measured absolute density of sintered porous Fe-28Mn-3Si alloys. The weight of both the green and sintered compacts was measured using a precision electronic balance (KINO, Norcross, GA, USA). The weight loss is expressed as $\left(m_{0}-m_{1}\right) / m_{0}$, where $m_{0}$ is the weight of the green compacts before sintering, while $m_{1}$ is the weight of the corresponding specimens after sintering. The microstructure and morphologies of the sintered PM alloys were examined using a scanning electron microscope (SEM, Quanta 200F, FEI, Hillsboro, OR, USA) attached with an X-ray energy dispersive spectrometer (EDS). An X-ray diffractometer (XRD D2 Phaser, Bruker, Karlsruhe, Germany) with $\mathrm{Cu} K \alpha$ radiation $(\lambda=1.54 \AA$ ) was used to analyse the phase compositions of the PM compacts at room temperature. A universal testing machine (Instron 3367, Norwood, MA, USA) equipped with an extensometer was used to measure the tensile properties of the sintered PM parts. The tensile bars were flat dog-bone shaped specimens cut from the sintered blocks. The gauge length of the tensile bars was $8 \mathrm{~mm}$ and the size of the cross-section was $13 \mathrm{~mm} \times 3 \mathrm{~mm}$. The tensile testing was measured at a cross-head speed of $0.2 \mathrm{~mm} / \mathrm{min}$, equivalent to an initial strain rate of $4.2 \times 10^{-3} \mathrm{~s}^{-1}$.

\subsection{Principle to Calculate the Vapor Pressure}

The equilibrium partial pressure $\left(P_{i}^{e}\right)$ of an element in the ternary system can be expressed as:

$$
P_{i}^{e}=\alpha_{i} \cdot P_{i}
$$

where $\alpha_{i}$ and $P_{i}$ are the activity and equilibrium vapor pressure of a pure element $i$, respectively. The values of $P_{\mathrm{Fe}}, P_{\mathrm{Mn}}$, and $P_{\mathrm{Si}}$ are $6.3 \times 10^{-2}, 78$, and $8.7 \times 10^{-2} \mathrm{~Pa}$ at $1200{ }^{\circ} \mathrm{C}$, which is determined according to reference [33].

The activity of element $i$ is given as:

$$
a_{i}=\exp \left(\frac{\mu_{i}-\mu_{i}^{0}}{R T}\right)
$$


where $\mu_{i}$ is the chemical potential of $i$ in a certain state, $\mu_{i}^{0}$ is the chemical potential of $i$ in the standard state, $R$ is the gas constant, and $T$ is the temperature in $K$. Therefore, the activity is 1 for a pure element in the standard state.

The chemical potential of element $i$ is calculated from the Gibbs energy:

$$
\mu_{i}=\left(\frac{\partial_{G}}{\partial_{n i}}\right)_{T, P, n_{j}(j \neq i)}
$$

where the temperature $(T)$, pressure $(P)$, and composition of the other elements are constants.

At equilibrium, $\mu_{i}$ is the same value for all of the phases. For instance, the following relationship is fulfilled for a three-phase equilibrium $(\alpha+\beta+\gamma$ phases) in a ternary A-B-C system:

$$
\mu_{i}^{\alpha}=\mu_{i}^{\beta}=\mu_{i}^{\gamma}
$$

The Gibbs energy of a solution phase $(\varphi)$ in a ternary A-B-C system can be described by the Redlich-Kister polynomial [34]:

$$
\begin{gathered}
{ }^{0} G_{m}^{\varphi}=x_{A}^{0} G_{A}^{\varphi}+x_{B}^{0} G_{B}^{\varphi}+x_{C}{ }^{0} G_{C}^{\varphi}+R T\left(x_{A} \ln x_{A}+x_{B} \ln x_{B}+x_{C} \ln x_{C}\right)+x_{A} x_{B} L_{A, B}^{\varphi}+x_{B} x_{C} L_{B, C}^{\varphi} \\
+x_{A} x_{C} L_{A, C}^{\varphi}+{ }^{0} G_{A, B, C}^{\varphi}+{ }^{\Delta} G_{m a g}^{\varphi}
\end{gathered}
$$

where $x_{i}$ is the molar fraction of element $i,{ }^{0} G_{i}^{\varphi}$ is Gibbs energy at the standard state, the terms $L_{i, j}^{\varphi}(i, j=\mathrm{A}, \mathrm{B}, \mathrm{C})$ are the interaction parameters from the binary systems, ${ }^{0} G_{A, B, C}^{\varphi}$ is the excess Gibbs energy, and ${ }^{\Delta} G_{m a g}^{\varphi}$ is the magnetic contribution to the Gibbs energy.

The Gibbs energies of all phases in the Fe-Mn-Si system were given in Reference [35] using the CALPHAD method [36], used to calculate the activities of Fe, Mn, and Si of the ternary system in the present study.

\section{Results}

\subsection{Weight Loss and Chemical Composition}

Figure 2 shows the weight loss rate of the alloys sintered for different isothermal holding times. In general, the weight loss rate increases with the increase of the isothermal holding time. In detail, the weight loss of the sintered MM alloys with no isothermal holding is very mild, only $\sim 2 \mathrm{wt}$. $\%$. When the isothermal holding time increases to $1 \mathrm{~h}$, the weight loss increases significantly to $\sim 7.5 \mathrm{wt}$. \%, which is a $\sim 4$-fold increase compared to its counterpart with no isothermal holding. However, the weight loss rate of the alloys sintered for $2 \mathrm{~h}$ and $3 \mathrm{~h}$ increases by only $2 \mathrm{wt}$. $\%$ and $3 \mathrm{wt}$. $\%$, as compared with that sintered for $1 \mathrm{~h}$. This indicates that the weight loss mainly happens during the first hour of isothermal holding, and the weight loss rate decreases with the increase of the isothermal time.

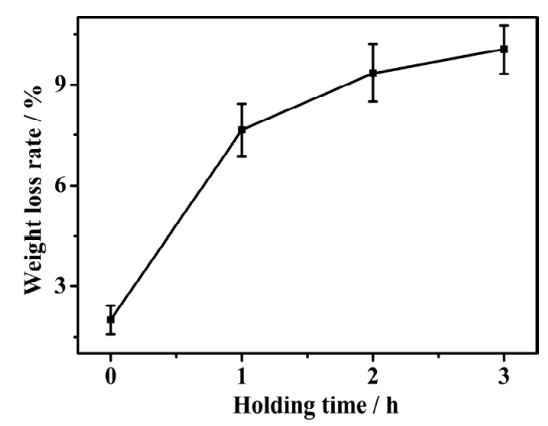

Figure 2. Weight loss rate of the sintered MM Fe-Mn-Si samples as a function of the isothermal holding time. 
EDS line scans were performed on the cross-sections of the sintered alloys to examine the distribution of Fe, Mn, and Si in the sintered Fe-Mn-Si alloys. As shown in Figure 3, the EDS line scan direction is perpendicular to sample surface-resin interface, and all scans were recorded from the sample surface to the middle of the cross-sections. Figures 4 and 5 illustrate two typical EDS line scan results of the alloys sintered for no isothermal holding and for $1 \mathrm{~h}$ isothermal holding. It can be seen that a Mn depletion layer exists on the surface of the sintered Fe-Mn-Si samples. The Mn content increases parabolically with the increase of the scan distance, starting from the resin-sample interface of the sintered samples until it is stabilized at $\sim 27.5 \mathrm{wt}$. \%. By contrast, the Si content is constant at $\sim 3.1 \mathrm{wt}$. \% for the scale of the entire distance. We define the scan distance $(x)$ between the resin-sample interface $(x=0)$ of the sintered samples and the location where the Mn content reaches a stable value $(\sim 27.5 \mathrm{wt} . \%)$ as the length of the Mn depletion region (LD). Table 1 presents the average surface chemical compositions and LD of the sintered alloys for different isothermal holding times at $1200{ }^{\circ} \mathrm{C}$. Interestingly, the LD increases with the increase of the isothermal holding time, as shown in Table 1. It is noted that the LD regions were removed from all the samples for the following microstructure observations (Section 3.4) and tensile testing (Section 3.5).

Table 1. The average chemical composition and Mn depletion region (LD) of the MM Fe-Mn-Si alloys sintered at $1200{ }^{\circ} \mathrm{C}$ for different isothermal holding times.

\begin{tabular}{|c|c|c|c|c|c|c|c|c|c|}
\hline \multirow{2}{*}{$\begin{array}{l}\text { Holding } \\
\text { Time/h }\end{array}$} & \multicolumn{4}{|c|}{ Chemical Composition on the Surface $x=0$ (wt. \%) } & \multirow{2}{*}{$\mathrm{LD}(\mu \mathrm{m})$} & \multicolumn{4}{|c|}{ Chemical Composition (wt. \%) at Positions $\geq$ LD } \\
\hline & Mn & Si & $\mathbf{O}$ & $\mathbf{F e}$ & & Mn & Si & $\mathbf{O}$ & $\mathrm{Fe}$ \\
\hline 0 & $1.12 \pm 0.12$ & $3.21 \pm 0.03$ & $0.45 \pm 0.04$ & Bal. & $12 \pm 5$ & $27.65 \pm 0.38$ & $3.07 \pm 0.04$ & $0.45 \pm 0.03$ & Bal. \\
\hline 1 & $1.14 \pm 0.08$ & $3.18 \pm 0.06$ & $0.43 \pm 0.07$ & Bal. & $405 \pm 29$ & $27.58 \pm 0.41$ & $3.09 \pm 0.06$ & $0.39 \pm 0.06$ & Bal. \\
\hline 2 & $1.19 \pm 0.09$ & $3.09 \pm 0.05$ & $0.46 \pm 0.07$ & Bal. & $445 \pm 31$ & $27.67 \pm 0.38$ & $3.11 \pm 0.04$ & $0.47 \pm 0.08$ & Bal. \\
\hline 3 & $1.13 \pm 0.07$ & $3.11 \pm 0.06$ & $0.47 \pm 0.05$ & Bal. & $500 \pm 36$ & $27.49 \pm 0.45$ & $3.05 \pm 0.09$ & $0.42 \pm 0.09$ & Bal. \\
\hline
\end{tabular}

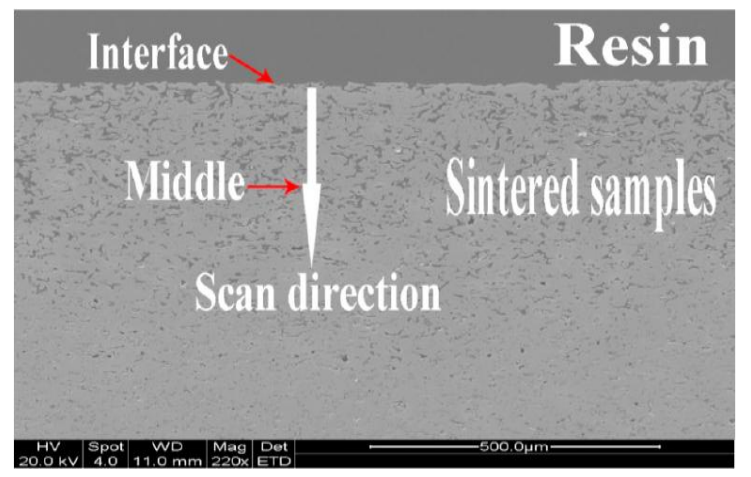

Figure 3. Morphologies of the cross-section of the MM Fe-28Mn-3Si alloys sintered at $1200{ }^{\circ} \mathrm{C}$ for $1 \mathrm{~h}$.

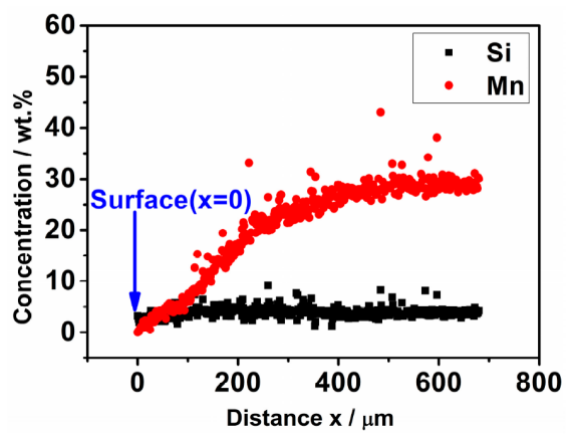

Figure 4. Mn and Si concentration of the cross-section of the MM Fe-Mn-Si alloys sintered at $1200{ }^{\circ} \mathrm{C}$ for $1 \mathrm{~h}$ isothermal holding. 


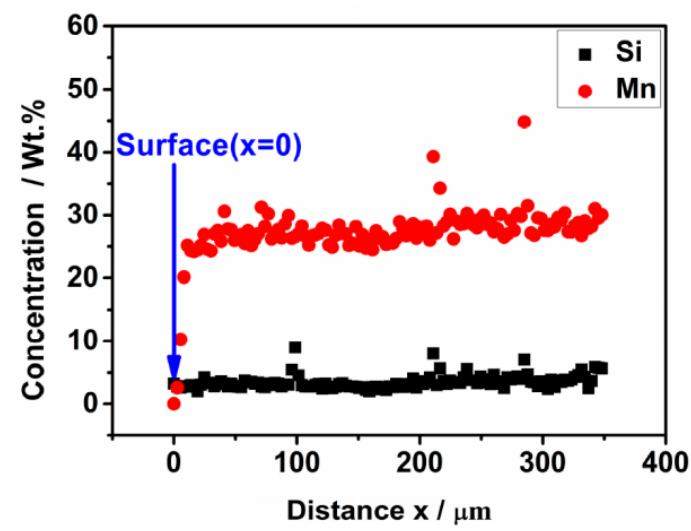

Figure 5. Mn and Si concentration on the cross-section of the MM Fe-Mn-Si alloys sintered at $1200{ }^{\circ} \mathrm{C}$ with no isothermal holding.

\subsection{Density and Porosity}

Figure 6 shows the evolution of the relative densities and open porosities of the Fe-28Mn-3Si alloys sintered at $1200^{\circ} \mathrm{C}$ as a function of the isothermal holding time. A drastic increase of the relative density occurs in the alloy sintered for $1 \mathrm{~h}$. In detail, the relative density of the alloys sintered for $1 \mathrm{~h}$ is approximately $80 \%$, an increase of $11 \%$ as compared to those with no isothermal holding. However, the excessive holding time only plays a limited role in improving the sintered density. For example, the density in the alloy sintered for $3 \mathrm{~h}$ is $\sim 85 \%$, which increases by only $\sim 4 \%$ and $\sim 1 \%$ with respect to their counterparts sintered for 1 and $2 \mathrm{~h}$, respectively.

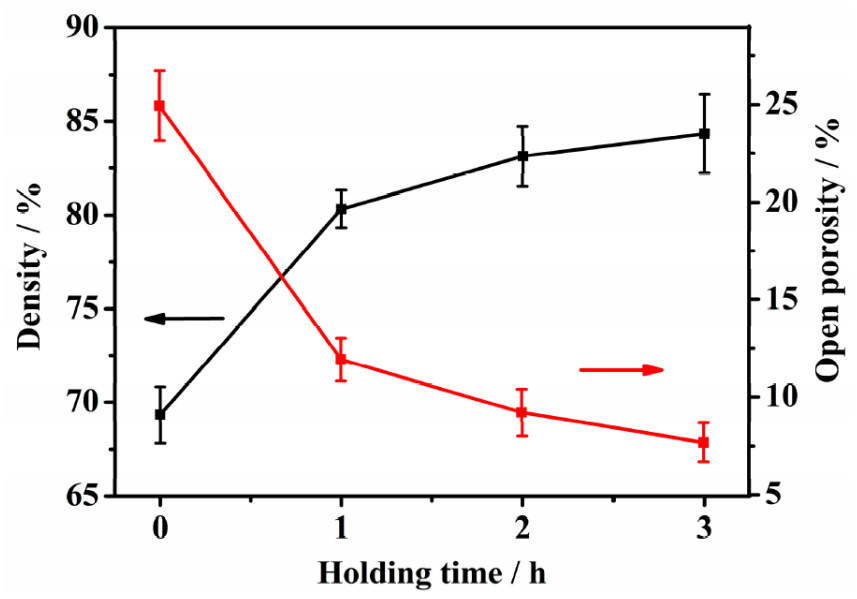

Figure 6. Relative densities and open porosities of the Fe-Mn-Si compacts sintered at $1200{ }^{\circ} \mathrm{C}$ as a function of the isothermal holding time.

In general, the open porosities of all the sintered alloys decrease with the increase of the isothermal holding time. The open porosity in alloys sintered with no isothermal holding is approximately $25 \%$. When the isothermal holding time extends to $1 \mathrm{~h}$, the open porosities sharply reduce to $12 \%$. However, further increasing the isothermal holding time to $2 \mathrm{~h}$ or $3 \mathrm{~h}$ only has a limited effect on eliminating the open porosities.

\subsection{Phase Identification}

Figures 7 and 8 present the XRD results on the surface and the middle parts (outside the LD region) of the sintered ternary Fe-Mn-Si alloys, respectively. The surface region of all the sintered 
alloys presents a single $\alpha$-Fe phase, regardless of the duration of the isothermal holding time (Figure 7). Figure 8 reveals that no peaks belonging to Fe, Mn, or Si are observed in the locations beyond LD. This indicates that both Mn and Si have been dissolved in the Fe-Matrix at the ramp stage. It is also noted that all the sintered alloys consist of a duplex major $\gamma$-austenite and minor $\varepsilon$-martensitic phase, as shown in Figure 8.

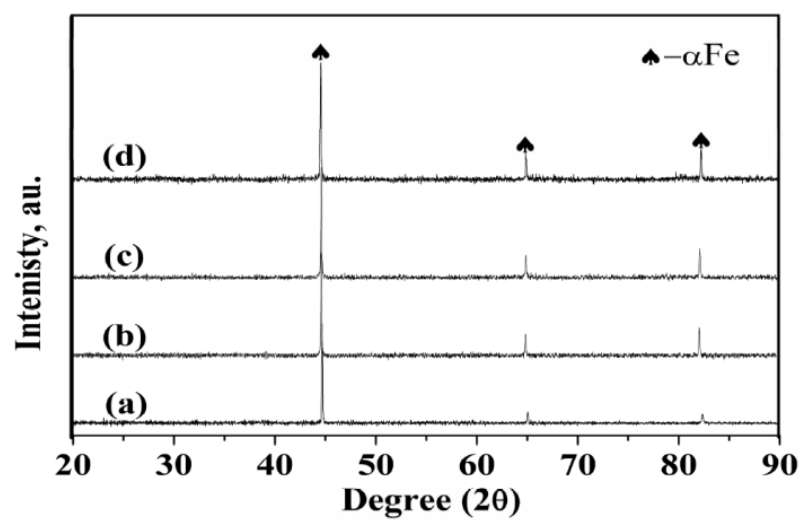

Figure 7. X-Ray Diffraction (XRD) results on the surface of the ternary Fe-28Mn-3Si alloys sintered at $1200{ }^{\circ} \mathrm{C}$ for different isothermal holding times. (a) MM alloys without isothermal holding; (b) MM alloys with $1 \mathrm{~h}$ isothermal holding; (c) MM alloys with $2 \mathrm{~h}$ isothermal holding; (d) MM alloys with $3 \mathrm{~h}$ isothermal holding.

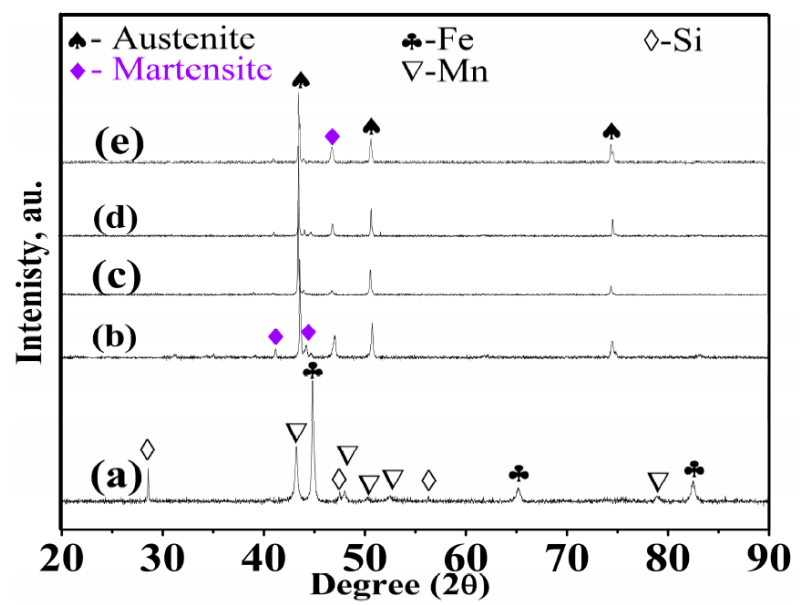

Figure 8. XRD results on the middle parts (outside the LD region) of the ternary Fe-28Mn-3Si alloys sintered at $1200{ }^{\circ} \mathrm{C}$ for different isothermal holding times. (a) Green compact before sintering; (b) MM alloys without isothermal holding; (c) MM alloys with $1 \mathrm{~h}$ isothermal holding; (d) MM alloys with $2 \mathrm{~h}$ isothermal holding; (e) MM alloys with $3 \mathrm{~h}$ isothermal holding.

\subsection{Microstructure}

Figure 9 shows the SEM graphs of the Fe-28Mn-3Si alloys sintered at $1200{ }^{\circ} \mathrm{C}$ as a function of the holding time. Figure 9a illustrates that a large number of interconnected irregular pores are distributed in the alloys with no isothermal holding, indicating that sintering at this stage is incomplete. When the holding time increases to $1 \mathrm{~h}$, the pore size as well as the overall porosities, especially the open porosities, reduce to a large extent. However, most of the pores still exhibit an irregular shape. As long as the isothermal holding time increases to $2 \mathrm{~h}$, the pore size further decreases, and some pores become spherical and isolated. The morphology of the alloys sintered for $3 \mathrm{~h}$ is similar to that sintered for $2 \mathrm{~h}$. 
However, more isolated and spherical pores are observed in the alloys sintered for $3 \mathrm{~h}$, as shown in Figure 9d.
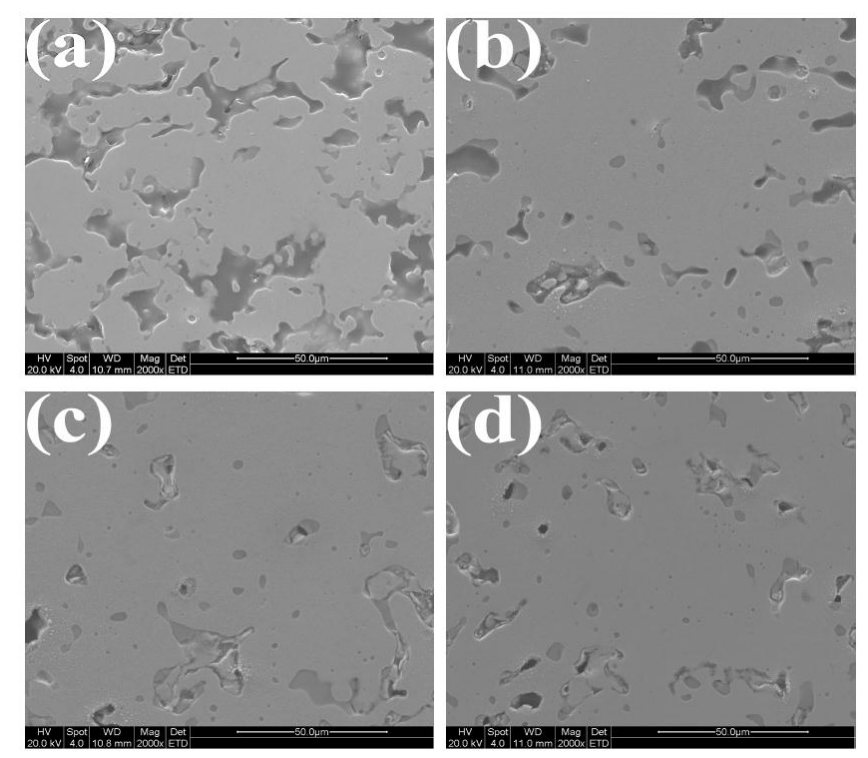

Figure 9. Morphology of the MM Fe-Mn-Si compacts sintered at $1200{ }^{\circ} \mathrm{C}$ for various isothermal holding times: (a) no isothermal holding; (b) $1 \mathrm{~h}$; (c) $2 \mathrm{~h}$; (d) $3 \mathrm{~h}$.

\subsection{Tensile Properties}

Figure 10 and Table 2 illustrate the stress-strain curves and the tensile properties of the sintered alloys with different holding times. As shown in Table 2, the isothermal holding time plays an important role in upgrading the tensile properties of the sintered Fe-Mn-Si compacts. In detail, the ultimate tensile strength (UTS) and fracture strain of the alloys sintered for $1 \mathrm{~h}$ are $258 \mathrm{MPa}$ and $6.4 \%$, which are $\sim 2$ times and $\sim 3$ times higher, respectively, than their counterparts with no isothermal holding. However, a further extended sintering time only has a limited effect on improving the tensile properties. Taking the UTS for example, the UTS of the alloys sintered for $3 \mathrm{~h}$ is $330 \mathrm{MPa}$, which is slightly higher than that of the sintered sample for $2 \mathrm{~h}(310 \mathrm{MPa})$.

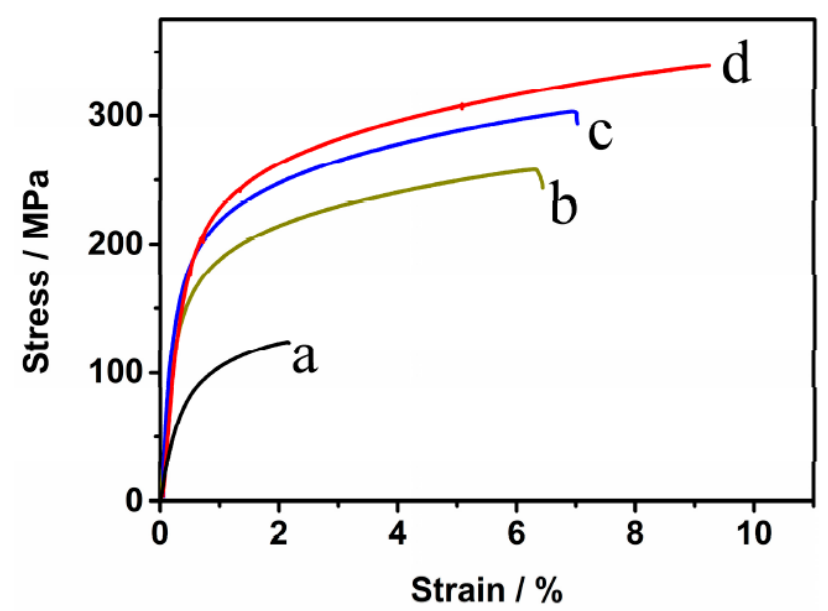

Figure 10. Tensile stress-strain curves of the MM Fe-28Mn-3Si compacts sintered at $1200{ }^{\circ} \mathrm{C}$ for various isothermal holding times: (a) no isothermal holding; (b) $1 \mathrm{~h}$; (c) $2 \mathrm{~h}$; and (d) $3 \mathrm{~h}$. 
Table 2. Average static tensile properties of Fe-Mn-Si alloys sintered at $1200{ }^{\circ} \mathrm{C}$ for different isothermal holding times.

\begin{tabular}{ccccc}
\hline $\begin{array}{c}\text { Sintering } \\
\text { Temperature } /{ }^{\circ} \mathbf{C}\end{array}$ & $\begin{array}{c}\text { Holding } \\
\text { Time/h }\end{array}$ & $\begin{array}{c}\text { Ultimate Tensile } \\
\text { Strength/MPa }\end{array}$ & $\begin{array}{c}\text { Fracture } \\
\text { Strain/\% }\end{array}$ & $\begin{array}{c}\text { Young's } \\
\text { Modulus/GPa }\end{array}$ \\
\hline \multirow{2}{*}{1200} & 0 & $125 \pm 9$ & $2 \pm 1$ & $53 \pm 4$ \\
& 1 & $258 \pm 9$ & $6 \pm 1$ & $69 \pm 3$ \\
& 2 & $310 \pm 15$ & $8 \pm 1$ & $71 \pm 3$ \\
& 3 & $330 \pm 23$ & $9 \pm 1$ & $74 \pm 3$ \\
\hline
\end{tabular}

\section{Discussion}

\subsection{Weight Loss Mechanism}

Figure 2 shows that the weight loss rate of the samples sintered with no isothermal holding is $\sim 2 \%$, which is only $\sim 1 / 4$ of the sintered sample sintered for $1 \mathrm{~h}$. This reveals that the weight loss mainly occurs during the isothermal holding stage at $1200^{\circ} \mathrm{C}$. In other words, the weight loss in the entire sintering process can be approximately equal to that in the isothermal holding stage. In this case, we only discuss the weight loss in the isothermal holding stage.

Table 1 reveals that $\mathrm{Fe}, \mathrm{Mn}$, and $\mathrm{Si}$ are homogenously distributed, and the concentration of $\mathrm{Fe}, \mathrm{Mn}$, and $\mathrm{Si}$ is stabilized at $\sim 69 \mathrm{wt} . \%, 27 \mathrm{wt} . \%$, and $3.1 \mathrm{wt}$. \% if the detection point is located at a distance from the surface $\geq$ LD. This can be further supported by the EDS line scan results in Figures 4 and 5 . According to the XRD result (Figure 8) and the SEM micrographs (Figure 9), this composition is a typical solid $\gamma$-austenite phase. At the distance from the surface $<\mathrm{LD}$, the Si content stabilizes at $\sim 3.1 \%$, while the Mn content increases with increasing distance until it stabilizes at $\sim 27 \mathrm{wt}$. \%. The isothermal section of the ternary Fe-Mn-Si phase diagram [37] at $1200{ }^{\circ} \mathrm{C}$ reveals that these compositions are solid $\alpha$-Fe and $\gamma$-austenite depending on the composition. Based on the above discussion, the sublimation of Fe, Mn, and Si contributes to the weight loss of the ternary Fe-28Mn-3Si compacts at $1200{ }^{\circ} \mathrm{C}$.

The sublimation rate of a certain component in the bulk materials can be determined by the Langmuir theory, which is given as [38-40]:

$$
N_{i}=-K_{\mathrm{L}} \cdot \varepsilon \cdot P_{i}^{e} \sqrt{M_{i} / T}
$$

where $N_{i}$ is the sublimation rate $\left(\mathrm{g} \cdot \mathrm{cm}^{-2} \cdot \mathrm{s}^{-1}\right)$ of component $i, K_{\mathrm{L}}$ is the Langmuir constant, $\varepsilon$ is the condensation coefficient depending on the materials (for metals $\varepsilon=1$ ), $P_{i}^{e}$ is the partial pressure of component $i$ in the Fe-Mn-Si system, $M_{i}$ is the molecular weight of component $i$, and $T$ is the absolute temperature in $\mathrm{K}$.

In our case, all the samples were sintered at the same temperature $\left(120{ }^{\circ} \mathrm{C}\right)$. Therefore, according to Equation (6), the sublimation rate of component $i$ in the ternary Fe-Mn-Si system is determined by the partial pressure $P_{i}^{e}$ and $M_{i}$.

The partial pressure of Fe, Mn, and Si as a function of the Mn concentration (1 wt. \%-28 wt. \%) in the ternary Fe-Mn-Si alloys was calculated and is presented in Figure 11.

To evaluate the difference in the sublimation rate between these three components in the LD region of the ternary Fe-Mn-Si compacts, the sublimation rate ratio of the two components $i$ and $j$ can be calculated with Equation (7). As the $K_{\mathrm{L}}, \varepsilon$, and $T$ are constant in all of the Fe-Mn-Si compacts during sintering, the sublimation rate ratio $(B)$ is then given as,

$$
\mathrm{B}=\frac{N_{i}}{N_{j}}=\frac{P_{i}^{e} \sqrt{M_{i}}}{P_{j}^{e} \sqrt{M_{j}}}
$$

where $P_{\mathrm{Fe}}^{\mathrm{e}}, P_{\mathrm{Mn}}^{\mathrm{e}}$, and $P_{\mathrm{Si}}^{\mathrm{e}}$ at $1200{ }^{\circ} \mathrm{C}$ are shown in Figure 11 , while $M_{\mathrm{Fe}}, M_{\mathrm{Mn}}$, and $M_{\mathrm{Si}}$ are $56 \mathrm{~g} \cdot \mathrm{mol}^{-1}$, $55 \mathrm{~g} \cdot \mathrm{mol}^{-1}$, and $28 \mathrm{~g} \cdot \mathrm{mol}^{-1}$, respectively. 


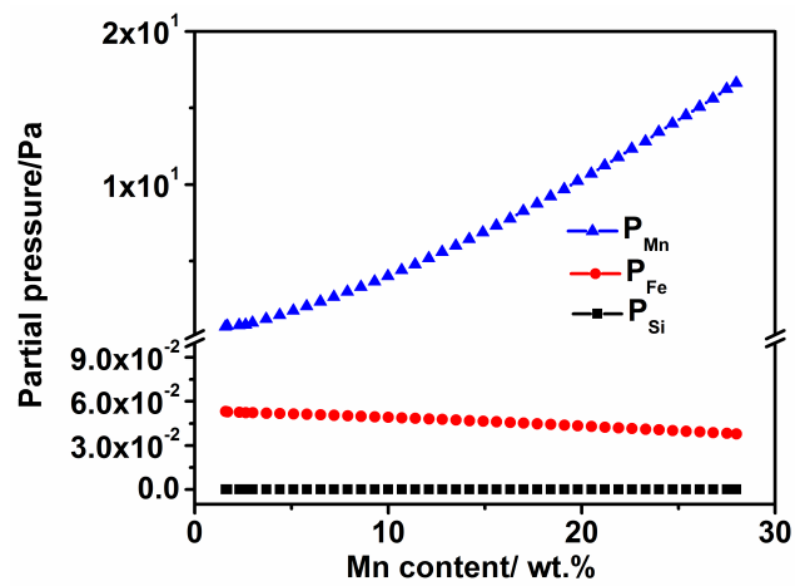

Figure 11. The partial pressure of $\mathrm{Fe}, \mathrm{Mn}$, and $\mathrm{Si}$ in Fe-Mn-Si sintered at $1200{ }^{\circ} \mathrm{C}$ as a function of Mn concentration.

Figure 12 shows that the sublimation rate of $\mathrm{Mn}$ is at least $3.41 \times 10^{5}$-fold higher than that of $\mathrm{Si}$ at all compositions in the ternary Fe-28Mn-3Si system, and the $N_{\mathrm{Mn}} / N_{\mathrm{Fe}}$ ratio ranges from 15 to 420 depending on the composition at a certain location in the Fe-28Mn-3Si compacts during sintering. A high ratio of $N_{\mathrm{Mn}} / N_{\mathrm{Si}}$ and $N_{\mathrm{Mn}} / N_{\mathrm{Fe}}$ reveals that the sublimation of the sintered Fe-Mn-Si compacts is mainly caused by the sublimation of Mn. Therefore, the Mn depletion regions (LD) exist in all the sintered compacts, as shown in Table 1 and Figure 4.

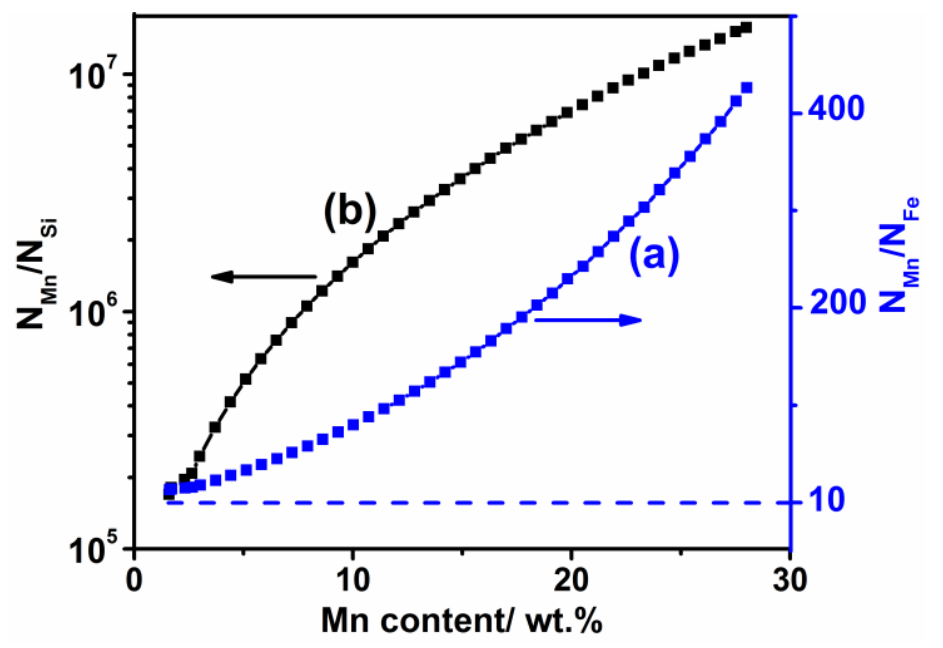

Figure 12. Sublimation rate ratio between the two different components in Fe-Mn-Si alloys at $1200{ }^{\circ} \mathrm{C}$.

(a) $N_{\mathrm{Mn}} / N_{\mathrm{Fe}} ;$ (b) $N_{\mathrm{Mn}} / N_{\mathrm{Si}}$.

It is noted that the weight loss of the sintered compacts isothermally held at the second and third hour is $\sim 1.7 \%$ and $\sim 1.1 \%$, respectively, which is only $\sim 1 / 3$ and $\sim 1 / 5$ of that of the holding at the first hour, as illustrated in Figure 2. This demonstrates that the sublimation rate of Mn decreases with the increase of the isothermal holding time. The change to the sublimation rate of the compacts sintered for different isothermal holding times may be caused by their different open porosities during sintering. This is because open pores create large amounts of walls in the interior of the compacts, which contribute to the sublimation of these components. Moreover, open pores are the flowing channels that move the Mn vapor from the interior areas to the outside of the porous samples.

The composition of the starting powder mixtures and sintering conditions (i.e., sintering temperature and heating rate) for all the samples are identical during isothermal holding, and the 
only difference between the compacts during sintering is the open porosities. It is therefore believed that a different volume of the open porosities leads to the decrease in the sublimation rate during isothermal holding.

The porous Fe-Mn-Si alloys with higher open pores present a higher sublimation rate due to the larger areas of open pore walls and more flowing channels for Mn vapor transfer. In our case, the volume of the open pores in the compacts sintered at the beginning of isothermal holding is $\sim 25 \%$, and it significantly decreases to $\sim 12 \%, 9 \%$, and $8 \%$ after $1 \mathrm{~h}, 2 \mathrm{~h}$, and $3 \mathrm{~h}$ of isothermal holding, respectively. The remarkably higher open pore volume during holding at the first hour gives rise to a significantly higher weight loss compared to that sintered at the second and third hour. By contrast, the number of open pores sintered for $2 \mathrm{~h}$ is only $\sim 3 \%$ higher than its $3 \mathrm{~h}$ counterparts. Thus, the weight loss of the Fe-Mn-Si compacts sintering at the second and the third hour is very limited compared with that sintered at the first hour.

\subsection{Densification}

It is recognised that the elimination of surface energy is the driving force for powder densification [20]. It is noted that the green density of the ball milled Fe-Mn-Si compacts was $\sim 65 \%$, as determined in reference [15]. The density of the sintered alloys with no holding was $\sim 5 \%$ higher than their green compacts. Alloying during heating is further demonstrated in the XRD result; a single $\gamma$-austenite phase was formed and the diffraction peaks indexed to $\alpha$-Fe, $\mathrm{Mn}$, and $\mathrm{Si}$ all disappear in the samples sintered without holding. Although MM does not cause alloying during milling [15], the much refined particles, larger particle surface areas, and stored strain energy during MM might assist in densification in the temperature rising stage.

Interestingly, a rapid densification of the Fe-Mn-Si compacts occurs at the first hour of isothermal holding. Figure 6 shows that the density of the compacts after $1 \mathrm{~h}$ isothermal holding increased by $11 \%$ compared to that with no isothermal holding. As discussed above, alloying was completed before the start of isothermal holding; therefore, the rapid densification of compacts at the first hour of isothermal holding may be driven by the diminution in the surface energy due to the reduction in the volume and the surface areas of the pores.

However, a further increase in isothermal holding time $(>1 \mathrm{~h})$ has a limited promotion in densification. This may be attributed to the following factors. Firstly, the remarkable decrease in open porosities contributes to the slow densification of the compacts when the isothermal holding time $>1 \mathrm{~h}$. This is confirmed in Figure 6. The significant decrease in the open porosities of the compacts sintered for longer than $1 \mathrm{~h}$ results in significant reduction in the surface area, and hence reduces the driving force. In addition, the Mn sublimation in the pores, especially in isolated pores, plays an important role in preventing the densification of the sintered alloys. Densification is a process of pore elimination. Published work reveals that the pore elimination depends on a balance between the surface energy in the curved surface of the pores and the gas pressure trapped in the pores [20]. For example, the pore shrinkage stops if the gas pressure trapped in the pores is larger than the surface energy on the surface of the pores. In our case, as shown in Figure 11, the partial pressure of the component Mn in the ternary Fe-Mn-Si alloys is as high as 16.6 Pa. In other words, the pressure in the pores is kept at 16.6 Pa during isothermal holding in high vacuum conditions. This inhibits the pore shrinkage, especially for the isolated pores, and consequently prevents the densification of the sintered compacts.

\subsection{Tensile Properties and Fracture}

As show in Table 2, the tensile properties of all the sintered PM alloys increase gradually with the increase of the isothermal holding time. The variation in tensile properties is attributed to the different porosities of the sintered alloys, which can be illustrated by the Gibson-Ashby model [41]:

$$
\frac{\sigma}{\sigma_{0}}=C_{1}\left(\frac{\rho}{\rho_{0}}\right)^{n_{1}}
$$




$$
\frac{E}{E_{0}}=C_{2}\left(\frac{\rho}{\rho_{0}}\right)^{n_{2}}
$$

where $\sigma$ and $\sigma_{0}$ are the tensile stress of the sintered and pore-free alloys, respectively, and $E$ and $E_{0}$ are the modulus of elasticity of the sintered and pore-free alloys, respectively. $\left(1-\rho / \rho_{0}\right)$ is the porosity and $\rho / \rho_{0}$ is the relative density, and $C_{1}, C_{2}, n_{1}$, and $n_{2}$ are material constants depending on the pore structure. The Gibson-Ashby relationship demonstrates that both the tensile strength and modulus of elasticity of the PM alloys increase with the decrease of porosities. Figure 6 shows that the porosities of all the sintered alloys decrease with the increase of the isothermal holding time. It is then expected that the tensile properties of the sintered alloys increase as the isothermal holding time increases. Data fitting reveals a linear relationship between $\log \left(\rho / \rho_{0}\right)$ and $\log \sigma$, with $R^{2}=1.00$ (see Figure 13 for details). This linear relationship is also observed for the plot of $\log \left(\rho / \rho_{0}\right) \mathrm{vs}$. $\log \mathrm{E}$ with $R^{2}=0.988$ (see Figure 14 for details). The extrapolation of these double logarithmic plots suggests a Young's modulus and tensile strength for a fully dense Fe-28Mn-3Si alloy as $\sim 96 \mathrm{GPa}$ and $740 \mathrm{MPa}$, respectively. This extrapolated Young's modulus is lower than the reported value of $E_{0}=175 \mathrm{GPa}$ for a (Twining-induced plasticity) TWIP steel [42], and the discrepancy might be because the Gibson-Ashby model is more suitable for porous materials with a porosity level $\geq 70 \%$ [41].

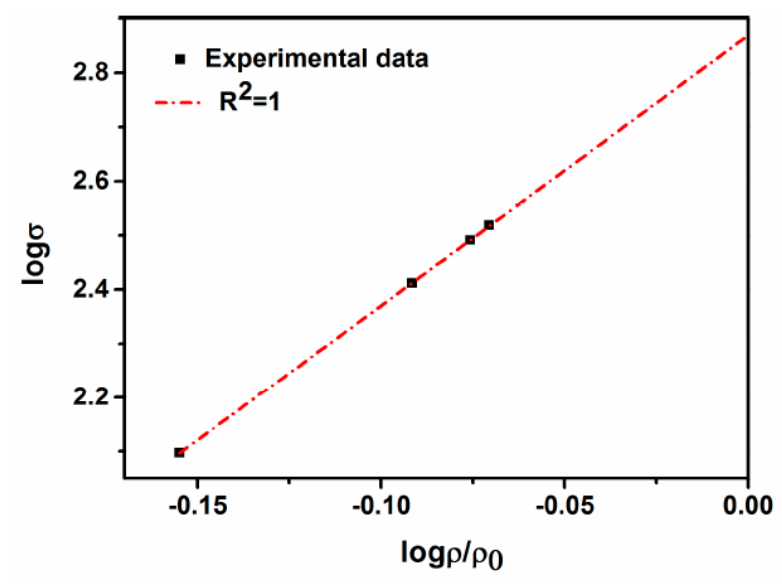

Figure 13. Change of the tensile strength $(\sigma)$ with relative density $\left(\rho / \rho_{0}\right)$ for the sintered alloys with different isothermal holding times.

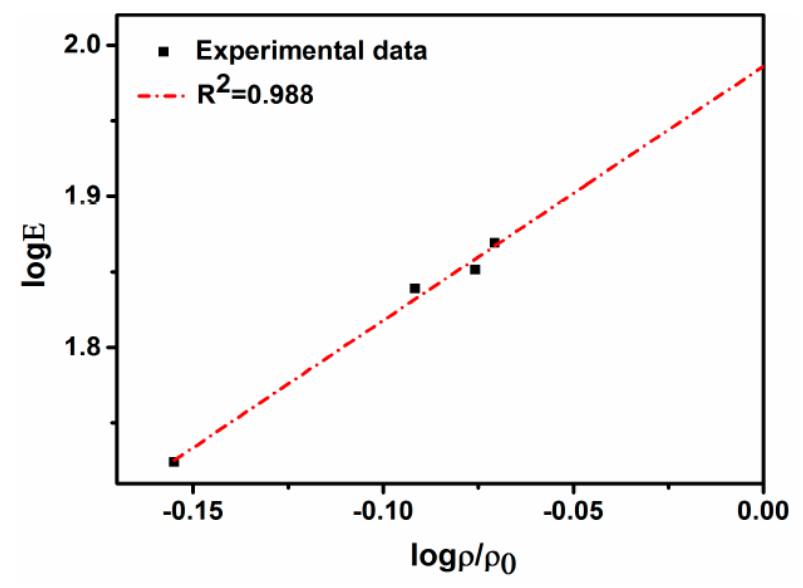

Figure 14. Change of the Young's modulus (E) with relative density $\left(\rho / \rho_{0}\right)$ for the sintered alloys with different isothermal holding times. 
Figure 15 presents the SEM images of the sintered Fe-Mn-Si alloys with various isothermal times. Shallow dimples are observed on the fracture surface of all of the sintered alloys. This indicates that all the sintered alloys exhibit ductile fracture. As shown in Figure 15, the number of dimples was similar in all the sintered alloys if the isothermal holding time is $>1 \mathrm{~h}$. This again reveals that the extension of the isothermal holding time has a limited effect on increasing the ductility of the Fe-Mn-Si compacts.
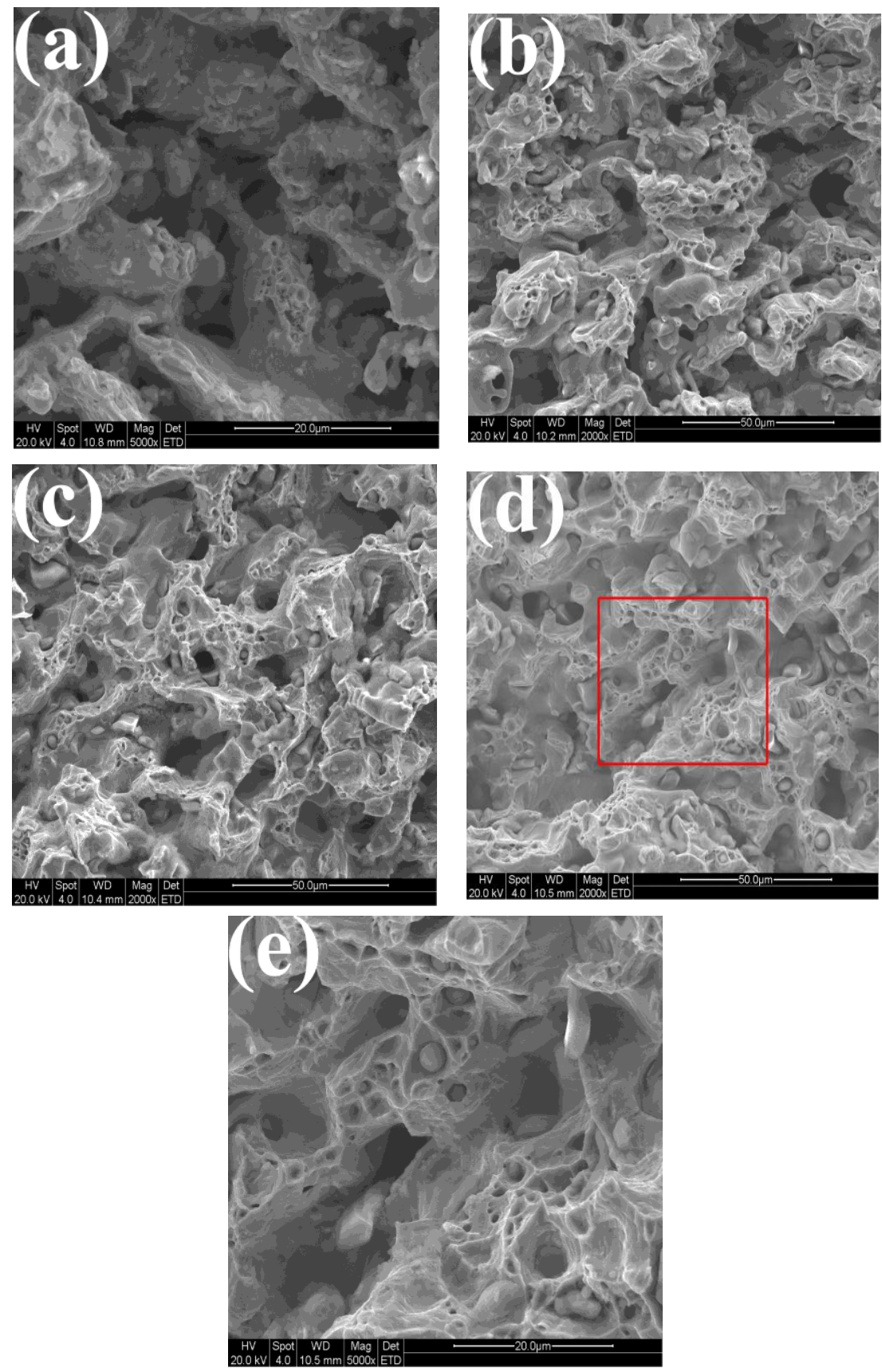

Figure 15. Fractography of the MM Fe-Mn-Si compacts sintered at $1200{ }^{\circ} \mathrm{C}$ for different isothermal holding times: (a) no isothermal holding; (b) 1 h; (c) 2 h; (d) 3 h; (e) enlarged area in (d).

\section{Conclusions}

This work presents the effect of the isothermal holding time on the densification, microstructure, weight loss behavior, and tensile properties of the sintered Fe-Mn-Si compact at $1200{ }^{\circ} \mathrm{C}$. The following key conclusions can be summarised. 
(1) The weight loss of the sintered Fe-Mn-Si compacts with no isothermal holding is only $~ 2 \%$. The weight loss of the sintered Fe-Mn-Si compacts increases significantly to $\sim 7.6 \%$ after the first hour of isothermal holding. A further increment in weight loss is very limited when the isothermal holding time is $>1 \mathrm{~h}$. An Mn depletion region exists on the surface layer of all of the sintered compacts. The length of the Mn depletion region (LD) increases with the increase of the isothermal holding time. The weight loss is mainly caused by the sublimation of Mn.

(2) The density of the sintered ternary Fe-Mn-Si alloys increases drastically during the first hour of isothermal holding, while densification slows down when the isothermal holding time is $>1 \mathrm{~h}$. The drop in open porosities mainly occurs during the first hour of isothermal holding.

(3) The surface of the sintered Fe-Mn-Si is comprised of a single $\alpha$-Fe phase. The sintered compacts in locations $\geq$ LD consist of a major $\gamma$-austenite and minor $\varepsilon$-martensite.

(4) The tensile properties of the sintered compacts increase with the increase of the sintering time. The tensile strength, elongation, and elasticity drastically increase from $125 \mathrm{MPa}, 2.1 \%$, and $52 \mathrm{GPa}$ for the samples with no isothermal holding to $258 \mathrm{MPa}, 6.4 \%$, and $69 \mathrm{GPa}$ for the samples with isothermal holding for $1 \mathrm{~h}$.

Acknowledgments: The China Scholarship Council (CSC) is gratefully acknowledged for providing a doctoral scholarship to $\mathrm{Xu}$, Zhigang.

Author Contributions: All authors were involved in designing the experiments. Zhigang Xu performed the sample preparation, data analysis, and manuscript writing and editing. Michael Hodgson contributed to manuscript proofreading. Dr. Keke Chang contributed to the thermodynamic calculation. Peng Cao contributed to data analysis and manuscript revision.

Conflicts of Interest: The authors declare no conflicts of interest.

\section{References}

1. Ölander, A. An electrochemical investigation of solid cadmium-gold alloys. J. Am. Chem. Soc. 1932, 54, 3819-3833. [CrossRef]

2. Jani, J.M.; Leary, M.; Subic, A.; Gibson, M.A. A review of shape memory alloy research, applications and opportunities. Mater. Des. 2014, 56, 1078-1113. [CrossRef]

3. Rao, A.; Srinivasa, A.; Reddy, J. Design of Shape Memory Alloy (SMA) Actuators, 1st ed.; Springer: New York, NY, USA, 2015; pp. 1-30.

4. Lee, W.; Weber, B.; Leinenbach, C. Recovery stress formation in a restrained Fe-Mn-Si-based shape memory alloy used for prestressing or mechanical joining. Constr. Build. Mater. 2015, 95, 600-610. [CrossRef]

5. Dasgupta, R. A look into Cu-based shape memory alloys: Present scenario and future prospects. J. Mater. Res. 2014, 29, 1681-1698. [CrossRef]

6. Dong, Z.; Kajiwara, S.; Kikuchi, T.; Sawaguchi, T. Effect of pre-deformation at room temperature on shape memory properties of stainless type Fe-15Mn-5Si-9Cr-5Ni-(0.5-1.5) NbC alloys. Acta Mater. 2005, 53, 4009-4018. [CrossRef]

7. Tanaka, Y.; Himuro, Y.; Kainuma, R.; Sutou, Y.; Omori, T.; Ishida, K. Ferrous polycrystalline shape-memory alloy showing huge superelasticity. Science 2010, 327, 1488-1490. [CrossRef] [PubMed]

8. Sato, A.; Kubo, H.; Maruyama, T. Mechanical properties of Fe-Mn-Si based SMA and the application. Mater. Trans. 2006, 47, 571-579. [CrossRef]

9. Cladera, A.; Weber, B.; Leinenbach, C.; Czaderski, C.; Shahverdi, M.; Motavalli, M. Iron-based shape memory alloys for civil engineering structures: An overview. Constr. Build. Mater. 2014, 63, 281-293. [CrossRef]

10. Sawaguchi, T.; Nikulin, I.; Ogawa, K.; Sekido, K.; Takamori, S.; Maruyama, T.; Chiba, Y.; Kushibe, A.; Inoue, Y.; Tsuzaki, K. Designing Fe-Mn-Si alloys with improved low-cycle fatigue lives. Scr. Mater. 2015, 99, 49-52. [CrossRef]

11. Xu, Z.; Hodgson, M.A.; Cao, P. A comparative study of powder metallurgical (PM) and wrought Fe-Mn-Si alloys. Mater. Sci. Eng. A 2015, 630, 116-124. [CrossRef]

12. Xu, Z.; Hodgson, M.A.; Cao, P. Microstructure and degradation behavior of forged Fe-Mn-Si alloys. Int. J. Mod. Phys. B 2015, 29, 1-6. [CrossRef] 
13. Liu, B.; Zheng, Y.; Ruan, L. In vitro investigation of Fe30Mn6Si shape memory alloy as potential biodegradable metallic material. Mater. Lett. 2011, 65, 540-543. [CrossRef]

14. Xu, Z.; Hodgson, M.A.; Cao, P. Effect of Immersion in Simulated Body Fluid on the Mechanical Properties and Biocompatibility of Sintered Fe-Mn-Based Alloys. Metals 2016, 6, 309. [CrossRef]

15. Xu, Z.; Hodgson, M.A.; Cao, P. Effects of Mechanical Milling and Sintering Temperature on the Densification, Microstructure and Tensile Properties of the Fe-Mn-Si Powder Compacts. J. Mater. Sci. Technol. 2016, 32, 1161-1170. [CrossRef]

16. Cintas, J.; Cuevas, F.; Montes, J.; Herrera, E. High-strength PM aluminium by milling in ammonia gas and sintering. Scr. Mater. 2005, 53, 1165-1170. [CrossRef]

17. McNeese, M.D.; Lagoudas, D.C.; Pollock, T.C. Processing of TiNi from elemental powders by hot isostatic pressing. Mater. Sci. Eng. A 2000, 280, 334-348. [CrossRef]

18. Angelo, P.; Subramanian, R. Powder Metallurgy: Science, Technology and Applications; PHI Learning Pvt. Ltd.: New Delhi, India, 2008.

19. Rahimian, M.; Parvin, N.; Ehsani, N. The effect of production parameters on microstructure and wear resistance of powder metallurgy $\mathrm{Al}_{-} \mathrm{Al}_{2} \mathrm{O}_{3}$ composite. Mater. Des. 2011, 32, 1031-1038. [CrossRef]

20. German, R.M. Powder Metallurgy and Particulate Materals Processing: The Processes, Materials, Products, Properties and Applications, 1st ed.; Metal Powder Industries Federation: Princeton, NJ, USA, 2005; pp. 221-260.

21. Suryanarayana, C. Mechanical alloying and milling. Prog. Mater Sci. 2001, 46, 1-184. [CrossRef]

22. Zhu, M.; Dai, L.; Gu, N.; Cao, B.; Ouyang, L. Synergism of mechanical milling and dielectric barrier discharge plasma on the fabrication of nano-powders of pure metals and tungsten carbide. J. Alloys Compd. 2009, 478, 624-629. [CrossRef]

23. Gheisari, K.; Javadpour, S.; Oh, J.; Ghaffari, M. The effect of milling speed on the structural properties of mechanically alloyed Fe-45\%Ni powders. J. Alloys Compd. 2009, 472, 416-420. [CrossRef]

24. Garroni, S.; Enzo, S.; Delogu, F. Mesostructural refinement in the early stages of mechanical alloying. Scr. Mater. 2014, 83, 49-52. [CrossRef]

25. Zhang, Z.; Sandström, R.; Frisk, K.; Salwén, A. Characterization of intermetallic Fe-Mn-Si powders produced by casting and mechanical ball milling. Powder Technol. 2003, 137, 139-147. [CrossRef]

26. Liu, T.; Liu, H.; Zhao, Z.; Ma, R.; Hu, T.; Xie, Y. Mechanical alloying of Fe-Mn and Fe-Mn-Si. Mater. Sci. Eng. A 1999, 271, 8-13. [CrossRef]

27. Saito, T.; Kapusta, C.; Takasaki, A. Synthesis and characterization of Fe-Mn-Si shape memory alloy by mechanical alloying and subsequent sintering. Mater. Sci. Eng. A 2014, 592, 88-94. [CrossRef]

28. Šalak, A.; Selecka, M.; Bureš, R. Manganese in ferrous powder metallurgy. Powder Metall. Prog. 2001, 1, 41-58.

29. Hryha, E.; Dudrova, E.; Nyborg, L. Critical aspects of alloying of sintered steels with manganese. Metall. Mater. Trans. A 2010, 41, 2880-2897. [CrossRef]

30. Hryha, E.; Gierl, C.; Nyborg, L.; Danninger, H.; Dudrova, E. Surface composition of the steel powders pre-alloyed with manganese. Appl. Surf. Sci. 2010, 256, 3946-3961. [CrossRef]

31. Xu, Z.; Hodgson, M.A.; Cao, P. Weight loss behavior of a vacuum sintered powder metallurgical Fe-Mn-Si alloy. J. Mater. Res. 2017, 32, 644-655. [CrossRef]

32. American Society for Testing and Materials (ASTM) International. ASTM B962-14, Standard Test Methods for Density of Compacted or Sintered Powder Metallurgy (PM) Products Using Archimedes' Principle; ASTM International: West Conshohocken, PA, USA, 2014; p. 7.

33. Lide, D.R. CRC Handbook of Physics and Chemistry, 85th ed.; CRC Press: Boca Raton, FL, USA, 2004.

34. Redlich, O.; Kister, A. Algebraic representation of thermodynamic properties and the classification of solutions. Ind. Eng. Chem. 1948, 40, 345-348. [CrossRef]

35. Forsberg, A.; Ågren, J. Thermodynamic evaluation of the Fe-Mn-Si system and the $\gamma / \varepsilon$ martensitic transformation. J. Phase Equilib. 1993, 14, 354-363. [CrossRef]

36. Saunders, N.; Miodownik, A.P. CALPHAD (Calculation of Phase Diagrams): A Comprehensive Guide; Pergamon: Oxford, UK, 1998; Volume 1, pp. 1-100.

37. Raghavan, V.; Raynor, G.V.; Rivlin, V.G. Phase Diagrams of Ternary Iron Alloys; Indian Institute of Metals: New Delhi, India, 1987; pp. 363-377.

38. Jones, H.A.; Mackay, G. The rates of evaporation and the vapor pressures of tungsten, molybdenum, platinum, nickel, iron, copper and silver. Phys. Rev. 1927, 30, 201. [CrossRef] 
39. Langmuir, I. Vapor pressures, evaporation, condensation and adsorption. J. Am. Chem. Soc. 1932, 54, 2798-2832. [CrossRef]

40. Chen, G.; Cao, P.; He, Y.; Shen, P.; Gao, H. Effect of aluminium evaporation loss on pore characteristics of porous FeAl alloys produced by vacuum sintering. J. Mater. Sci. 2012, 47, 1244-1250. [CrossRef]

41. Gibson, L.J.; Ashby, M.F. Cellular Solids: Structure and Properties, 2nd ed.; Cambridge University Press: Cambridge, UK, 1999; pp. 100-200.

42. Kim, J.; Lee, S.-J.; de Cooman, B.C. Effect of Al on the stacking fault energy of F-18Mn-0.6C twinning-induced plasticity. Scr. Mater. 2011, 65, 363-366. [CrossRef]

(c) 2017 by the authors. Licensee MDPI, Basel, Switzerland. This article is an open access article distributed under the terms and conditions of the Creative Commons Attribution (CC BY) license (http:/ / creativecommons.org/licenses/by/4.0/). 